\title{
FLORA VAGINAL E CORRELAÇÃO COM ASPECTOS CITOLÓGICOS*
}

\author{
Hygia Maria Nunes Guerreiro * * \\ Helenemarie Schaer Barbosa * * \\ João Lycio Conceição Filho ** \\ Lúcia Maria Tishchenko* * \\ Suraia Hagge * *
}

\begin{abstract}
GUERREIRO, H.M.N. et al. Flora vaginal e correlação com aspectos citológicos. Rev.Saúde públ., S. Paulo, $20: 415-20,1986$.

RESUMO: Com a finalidade de esclarecer a patogenicidade de microorganismos que compōem a microflora vaginal, particularmente nas chamadas vaginites inespecíficas e de determinar o valor da citologia como método para identificação da flora vaginal, foram estudadas 97 pacientes, realizando cultura, exame direto a fresco, Gram e citologia do material cérvico-vaginal. Entre os microorganismos de importância clínica reconhecida, Gardnerella vaginalis foi o mais freqüentemente isolado, $48,4 \%$, seguido de Trichomonas vaginalis, 10,3\%, Candida albicans, 7,2\% e Neisseria gonorrhoeae, 1,1\%. Alteraçōes citológicas indicativas de cervicite e/ou vaginite estiveram presentes na maioria dos casos de G.vaginalis, C.albicans e em todos os casos de T.vaginalis. Foi ressaltada a importância da avaliação semi-quantitativa dos microorganismos nos meios de cultura. Na avaliaçāo da citologia como método diagnóstico para a microflora vaginal, foi observada que este foi o melhor dos métodos utilizados na identificação de T.vaginalis, tendo sido detectado cerca de $50 \%$ dos casos de C.albicans. No diagnóstico de G.vaginalis a citologia foi positiva em $48,9 \%$ dos casos, destacando-se que dos 31 casos positivos ao exame citológico, oito tiveram culturas negativas para G.vaginalis, embora tenham sido isolados nestes últimos: Haemophilus sp. ou Corynebacterium sp.
\end{abstract}

UNITERMOS: Vagina, microbiologia. Vagina, citologia. Vaginite, diagnóstico. Cervicite, diagnóstico.

\section{INTRODUÇĀO}

Numerosos trabalhos sobre microflora vaginal têm sido publicados $3,6,11,13,15$, isolando-se uma larga variedade de microorganismos aeróbios e anaeróbios, cujo papel patogênico tem sido amplamente discutido. Trichomonas vaginalis, Candida albicans, Neisseria gonorrhoeae, Gardnerella vaginalis e Chlamydia trachomatis são os patógenos mais freqüentemente relacionados às cervicites e vaginites 2,15 , enquanto bactérias como os Staphylococcus $s p$, os Streptococcus $s p$ e os Bacterióides sp têm sido identificados como constituintes da flora normal3,11,14. Não se pode, no entanto, esquecer o papel que inúmeros fatores desempenham no equilíbrio microorganismo-hospedeiro. Desta forma, C.albicans e $T$. vaginalis, patógenos reconhecidos, podem ser isolados de mulhe res sem sintomatologia clínica $10,15,16$, dificultando assim a interpretação do achado microbiológico. Também em mulheres sintomáticas ocasionalmente não se tem conseguido isolar um patógeno reconhecido2.

Devido à dificuldade em estabelecer o papel patogênico dos microorganismos que compõem a flora vaginal, procuramos correlacionar a microflora com a presença de colpocervicite, diagnosticada através do estudo do esfregaço citológico, objetivando esclarecer a relação agente etiológico versus doença.

Procuramos também, determinar a eficácia da citologia como método diagnóstico da microflora vaginal, através de um estudo comparativó entre o esfregaço citológico e os achados microbiológicos.

\section{MATERIAL E MÉTODOS}

Foi estudado material colhido de 97 pacientes do sexo feminino atendidas no ambulatório do Centro de Pesquisas da Maternidade Climério de Oliveira, da Universidade Federal da Bahia. O material, colhido com "swab" de algodão, dos seguintes locais: fundo do saco vaginal, endocérvice, ectocérvice e uretra, foi suspenso em $0,2 \mathrm{ml}$ de solução fisiológica e semeado nos diferentes meios de cultura, em intervalo não superior a duas horas. Dessas suspensões eram realizados também o exame direto a fresco e o esfregaço corado pelo método de Gram. Para o exame citológico foram colhidos dois esfre-

* Pesquisa subvencionada pelo Conselho Nacional de Desenvolvimento Científico e Tecnológico (CNPq). Processo no $40.09+55 / 82$.

* Do Departamento de Farmácia Qualitativa da Faculdade de Farmácia da Universidade Federal da Bahia - Rua Barão do Jeremoabo, s/n? Campus, Ondina - 40000 - Salvador, BA - Brasil. 
gaços com espátula de madeira, um do material de fundo de saco vaginal e outro do cérvice, fixados em álcool a $95 \%$ e corados pelo método de Papanicolaou. O material de vagina, colo e uretra foi semeado nos meios de Agar sangue, Agar vaginalis4, Agar chocolate, Agar Thayer Martin e Agar Sabouraud, sendo que o de vagina era semeado também em Agar Eosina Azul de Metileno (EMB). O Agar Sabouraud e o EMB foram acrescentados à rotina bacteriológica usual para o trato genital, na expectativa de isolamento de leveduras e enterobactérias, que acreditávamos ter uma incidência mais elevada. O Agar vaginalis foi acrescentado visando 0 isolamento de Gardnerella vaginalis.

A identificação das bactérias isoladas foi feita por métodos convencionais. Nos exames bacteriológicos, tanto na cultura quanto na bacterioscopia, foi feita uma avaliação semi-quantitativa das bactérias, classificando-as entre numerosas e raras. A identificação de leveduras foi dirigida para C.albicans, identificada pelo teste do tubo germinativo. As leveduras identificadas como Candida sp., pelo aspecto microscópico-morfológico a partir do meio de Cornmeal e cujos resultados no teste do tubo germinativo foram negativos, foram agrupados como Candida sp. Na interpretação dos esfregaços citológicos, para caracterizar a presença de inflamação, foram considerados o número de leucócitos, a presença de macrófagos e células gigantes multinucleadas e as alterações inflamatórias presentes nas células epiteliais ${ }^{19}$.

A todas as pacientes foi aplicado um questionário visando obter dados como idade, escolaridade, atividade sexual, uso de métodos contraceptivos entre outros.

\section{RESULTADOS}

A faixa etária da população estudada variou de 16 a 50 anos, sendo a idade média 33 anos.

Em sua maior parte eram mulheres com baixo grau de escolaridade: $37(38,1 \%)$ eram analfabetas, $23(23,7 \%)$ tinham primário incomple to e $16(16,5 \%)$ haviam feito o curso primário completo. Apenas duas tinham nivel universitário e as restantes enquadravam-se entre o $1 \%$ e 2 ? graus.

A maioria das mulheres era de baixo nível sócio-econômico uma vez que $76(78,3 \%)$ relataram uma renda familiar inferior a três salários mínimos. Quanto à cor, $55(56,7 \%)$ ezam pardas, $30(30,9 \%)$ brancas e $15(15,5 \%)$ negras.

A maioria, 94(97\%), referiu um único parceiro sexual. No que se refere ao uso de contraceptivos, $57(58,7 \%)$ não usavam nenhum tipo, $20(20,6 \%)$ faziam uso de dispositivo intra-uterino, $10(10,3 \%)$ usavam anticoncepcional oral e $11(11,3 \%)$ haviam feito ligadura de trompas uterinas.
Com relação à profissão, $57(58,8 \%)$ eram donas de casa enquanto $18(18,5 \%)$ tinham profissões não especializadas.

Quanto às características da flora vaginal das pacientes estudadas, a Tabela 1 relaciona os microorganismos encontrados. As bactérias do gênero Corynebacterium, Staphylococcus e G.vaginalis foram as mais freqüentemente isoladas: $73,2 \%, 52,6 \%$ e $47,4 \%$, respectivamente.

\section{TABELA 1}

Freqüência de Microorganismos na Microflora Vaginal das 97 Pacientes Estudadas.

\begin{tabular}{|c|c|c|}
\hline Microorganismos & \multicolumn{2}{|c|}{ Ocorrência } \\
\hline Corynebacterium sp. & 76 & 78,3 \\
\hline Staphylococcus epidermidis & 51 & 52,6 \\
\hline Gardnerella vaginalis & 47 & 48,4 \\
\hline Lactobacillus sp. & 35 & 36,1 \\
\hline Streptococcus não hemolítico * & 26 & 32,0 \\
\hline Micrococcus sp. & 21 & 21,6 \\
\hline Streptococcus beta hemolítico * & 14 & 14,4 \\
\hline Streptococcus viridans * & 10 & 10,3 \\
\hline Trichomonas vaginalis & 10 & 10,3 \\
\hline Escherichia coli & 9 & 9,3 \\
\hline Haemophilus sp. & 9 & 9,3 \\
\hline Leveduras não identificadas. & 8 & 8,2 \\
\hline Staphylococcus aureus & 8 & 8,2 \\
\hline Streptococcus grupo D não enterococos & 7 & 7,2 \\
\hline Streptococcus grupo D enterococos & 7 & 7,2 \\
\hline Candida albicans & 7 & 7,2 \\
\hline Candida sp & 5 & 5,2 \\
\hline Streptococcus grupo B & 4 & 4,1 \\
\hline Neisseria gonorrhoeae & 1 & 1,0 \\
\hline Citrobacter sp. & 1 & 1,0 \\
\hline Aeromonas sp. & 1 & 1,0 \\
\hline Pseudomonas sp. & 1 & 1,0 \\
\hline Moraxella sp. & 1 & 1,0 \\
\hline
\end{tabular}

- Estão nesta categoria os Streptococcus não classificados nos grupos B e D.

No que se refere à presença de processo inflamatório, de acordo com o resultado do exame citológico, 87 pacientes apresentavam alteraçōes inflamatórias em vagina e/ou cérvice, enquanto em apenas 10 pacientes não foram encontradas tais alterações. Quando se comparou a flora bacteriana destes dois grupos (Tabela 2), as diferenças mais marcantes foram no isolamento de Lactobacillus sp., que esteve associado à ausência de processo inflamatório $(\mathrm{P}<0,1)$, e de $G$.vaginalis, que foi mais freqüente- 
mente isolada de pacientes com vaginite e/ou cervicite, embora não se tenha encontrado significado estatístico pelo teste de Qui Quadrado $(\mathbf{P}>0,1)$.

\section{TABELA 2}

Frequência de Microorganismos na Microflora Vaginal de Acordo com a Presença ou Ausência de Processo Inflamatório

\begin{tabular}{lrrrr}
\hline \multicolumn{1}{c}{ Microorganismos } & \multicolumn{2}{c}{ Processo } \\
Inflamatório & $\begin{array}{c}\text { Ausência de } \\
\text { Processo } \\
\text { Inflamatório }\end{array}$ \\
& No & $\%$ & & \\
\hline Corynebacterium sp. & 68 & 78,1 & 8 & 80 \\
Staphylococcus epidermidis & 47 & 54,0 & 4 & 40 \\
Gardnerella vaginalis & 44 & 50,6 & 3 & 30 \\
Lactobacillus sp. & 29 & 33,3 & 6 & 60 \\
Streptococcus não hemolítico & 23 & 26,4 & 3 & 30 \\
Micrococcus sp. & 20 & 20,6 & 1 & 10 \\
Streptococcus beta hemolítico & 13 & 13,4 & 1 & 10 \\
Trichomonas vaginalis & 10 & 10,3 & 0 & 0 \\
Streptococcus viridans & 10 & 10,3 & 1 & 10 \\
Escherichia coli & 9 & 9,3 & 0 & 0 \\
Leveduras não identificadas & 8 & 8,2 & 0 & 0 \\
Streptococcus grupo D & & & & \\
não enterococos & 7 & 7,2 & 0 & 0 \\
Streptococcus grupo D & & & & \\
enterococos & 7 & 7,2 & 0 & 0 \\
Haemophilus sp. & 7 & 7,2 & 2 & 20 \\
Candida albicans & 6 & 6,2 & 1 & 10 \\
Staphylococcus aureus & 6 & 6,2 & 2 & 20 \\
Candida sp. & 5 & 5,7 & 0 & 0 \\
Streptococcus grupo B & 4 & 4,6 & 0 & 0 \\
Neisseria gonorrhoeae & 1 & 1,1 & 0 & 0 \\
Citrobacter sp. & 1 & 1,1 & 0 & 0 \\
Aeromonas sp. & 1 & 1,1 & 0 & 0 \\
Pseudomonas sp. & 1 & 1,1 & 0 & 0 \\
Moraxella sp. & 1 & 1,1 & 0 & 0 \\
\hline & & & &
\end{tabular}

T. vaginalis, Streptococcus do grupo $\mathrm{D}$, tanto enterococos como nāo enterococos, Escherichia coli, Streptococcus do grupo B, Candida sp., leveduras não identificadas, Neisseria gonorrhoeae, Citrobacter sp., Aeromonas sp., Pseudomonas sp. e Moraxella $s p$. foram encontrados apenas em pacientes com processo inflamatório.

Com a finalidade de obtermos uma avaliação mais real do significado de cada microorganismo presente no exame, procuramos fazer uma avalia. ção semiquantitativa da relação das bactérias entre si. Não se fez avaliação quantitativa de $T$. vaginalis. Nas leveduras a avaliação semi-quantitativa foi feita quando estas foram isoladas nos meios de cultura bacteriológicos, mas não quando isoladas apenas no meio de Agar Sabouraud.

Relacionamos separadamente os microorganismos reconhecidos como patogênicos e potencialmente patogênicos para $O$ trato genital feminino. Na categoria flora normal foram incluídos microorganismos como: Corynebacterium sp., Staphylococcus epidermidis, Lactobacillus sp., Micrococcus sp., Streptococcus sp. e leveduras8. Foram agrupados como patógeno em potencial aqueles cuja predominância era de microorganismos potencialmente patogênicos como Haemophilus sp., Candida sp. e Streptococcus dos grupos B e D. Nas 87 pacientes relacionadas na Tabela 3, que apresentaram alteraçóes inflamatórias ao exame citológico, $G$. vaginalis foi o microorganismo mais freqüentemente isolado, sendo predominante em $32,2 \%$ das pacientes. Embora não conste na Tabela 3, G. vaginalis foi isolada como bactéria predominante em três pacientes sem alterações in. flamatórias. Todos os casos com tricomoníase apresentavam alterações de inflamação e apenas um caso de C. albicans não apresentava tais alterações.

\section{TABELA 3}

Relação Entre Microorganismos Agrupados

Segundo Sua Patogenicidade e a Presença de Processo Inflamatório pela Citologia

\begin{tabular}{lrr}
\multicolumn{1}{c}{$\begin{array}{c}\text { Microorganismo } \\
\text { ou Grupo de } \\
\text { Microorganismo }\end{array}$} & \multicolumn{2}{c}{$\begin{array}{c}\text { Processo } \\
\text { Inflamatório }\end{array}$} \\
\hline No & $\%$ \\
\hline Gardnerella vaginalis predominante & 28 & 32,2 \\
Gardnerella vaginalis não predominante & 7 & 8,0 \\
Gardnerella vaginalis e/ou Trichomonas vagi- & & \\
nalis e/ou Candida albicans & 9 & 10,3 \\
Trichomonas vaginalis & 3 & 3,4 \\
Candida albicans & 2 & 2,3 \\
Neisseria gonorrhoeae & 1 & 1,1 \\
Patógeno em potencial & 9 & 10,3 \\
Flora normal & 27 & 31,0 \\
\hline
\end{tabular}

A fim de determinar o valor da citologia como método diagnóstico da microflora vaginal, foram comparados os resultados obtidos pelos exames microbiológicos com aqueles da citologia vaginal. Pôde-se observar que a eficiência deste método varia de acordo com o patógeno, como descreveremos a seguir.

\section{Bactérias}

Dentre as bactérias que apresentam um quadro citológico que permite um diagnóstico presuntivo, destacamos a G.vaginalis e a N.gonorrhoeae. Para a identificação de G.vaginalis levou-se em consideração a presença de células guias 2 ou fenômeno 
Gardner-Dukes, observando-se resultados compatíveis como G. vaginalis em 31 casos e obtendo-se a confirmação bacteriológica em 23 destes, dos quais 20 casos tiveram G. vaginalis isolada como microor. ganismo predominante. Nos oito casos restantes, vale ressaltar, foram isolados Haemophilus sp. como bactéria predominante em dois e Corynebacterüum sp. nos outros seis, ambos microorganismos com características morfológicas semelhantes à $G$. vaginalis. Entretanto, a cultura revelou um total de 47 amostras positivas para G.vaginalis, verificando-se que em 24 casos a citologia não apresentou aspectos que permitissem a identificação deste microorganismo. Dos casos não identificados pela citologia, 11 eram de G.vaginalis, predominante sem outro patógeno, enquanto que em 8 , embora houvesse predominância de G.vaginalis, outros microorganismos patogênicos foram também encontrados. Nos outros 5 casos G. vaginalis não era predominante. Uma única cultura foi positiva para N.gonorrhoeae. Entretanto, havia Corynebacterium sp. em predominância na cultura e a citologia foi sugestiva de $G$.vaginalis, não havendo aspectos indicativos de $N$. gonorrhoeae ${ }^{7}$. Embora não houvesse sido utilizado método microbiológico para a cultura de Chlamydia trachomatis, procurou-se pela citolo. gia identificar este microorganism $0^{5}$, não sendo encontrados aspectos diagnósticos.

\section{Trichomonas Vaginalis}

O maior número de casos foi detectado pela citologia que identificou 9 casos positivos. Destes,
7 foram positivos ao exame direto a fresco do material cérvico-vaginal, um foi positivo ao exame direto do material uretral, ficando apenas um caso de diagnóstico citológico de $T$. vaginalis sem confirmação pelo exame à fresco. $O$ exame direto à fresco do material cérvico-vaginal revelou um caso não identi. ficado pela citologia. Na investigação do material uretral à fresco foram encontrados mais dois casos de tricomoníase, não confirmados no material cér. vico-vaginal por qualquer das técnicas utilizadas.

\section{Candida e Outras Leveduras}

No conjunto de métodos utilizados, foram diagnosticados 20 casos positivos para leveduras. Destes, 12 apresentavam C. albicans ou Candida sp., sendo que em 6 , na qual foi feita uma avaliação semi-quantitativa, a quantidade presente foi considerada moderada ou superior12. A citologia fez o diagnóstico de 3 destes últimos. Dos 8 casos de outras leveduras, a citologia identific ou 2 casos, cuja quantidade foi considerada significativa. Os resultados da possivel interferência da utilização de contraceptivos na flora vaginal, comparando a microflora de 20 mulheres em uso de dispositivo intra-uterino e de 10 mulheres utilizando anticoncepcional oral, pareadas com 20 mulheres que não utilizavam qualquer contraceptivo, estão apresentados na Tabela 4. As mulheres do grupo controle foram escolhidas entre aquelas cujo material foi colhido na mesma semana das pacientes que utilizavam contraceptivo, e todas, nos três grupos, eram pacientes com vaginite e/ou cervicite.

TABELA 4

Correlação Entre Microflora Presente e o Método Contraceptivo Utilizado

\begin{tabular}{lrrrrrr}
\hline \multicolumn{1}{r}{ Microorganismo } & D.I.U. & \multicolumn{2}{c}{ Anticoncepcional Oral } & \multicolumn{2}{c}{ Controle } \\
& No & $\%$ & No & $\%$ & No & $\%$ \\
\hline Gardnerella vaginalis & 18 & 90 & 2 & 20 & 15 & 75 \\
Candida albicans & 2 & 10 & 1 & 10 & 3 & 15 \\
Trichomonas vaginalis & 2 & 10 & 2 & 20 & 2 & 10 \\
Flora normal & 1 & 05 & 4 & 40 & 4 & 20 \\
\hline
\end{tabular}

\section{DISCUSSÃO}

A flora bacteriana aeróbia das 97 mulheres deste estudo mostrou grande variedade de microorganis. mos, com pequenas variações em relação a outros trabalhos sobre flora bacteriana $6,17,20 . \mathrm{Na}$ tentativa de determinar os microorganismos efetivamente er. volvidos na patogenia de vaginites e cervicites, a variedade de agentes isolados nestes processos, assim como o complexo papel do equilíbrio ecológico da flora microbiana, torna bastante difícil a interpretação do significado de cada um destes agentes. Este tópico tem sido objeto de estudo de outros pesqui. sadores $10,11,13,20$, com os quais partilhamos a visão da importância da avaliação semi-quantitativa e da relação dos microorganismos entre si, como fundamental para a compreensão do problema.

$\mathrm{Na}$ microflora vaginal da população estudada foram encontrados C.albicans, T.vaginalis, N.gonorrhoeae e G.vaginalis, reconhecidos como micro- 
organismos freqüentemente envolvidos em processos infecciosos do trato genital. Quanto aos microrganismos potencialmente patogênicos, levamos em consideração não só o tipo de organismo encontrado, como também avaliamos o aspecto de predominância sobre a flora reconhecidamente normal. Foram encontradas bactérias, às quais se poderia atribuir papel patogênico devido à sua predominância sobre a flora normal: Haemophilus sp., Streptococcus dos grupos B e D e Citrobacter sp.

A avaliação da importância patogênica de Candida sp. ou outras leveduras tornou-se mais complexa devido ao fato de que a avaliação semi-quantitativa destas só foi feita quando do seu isolamento nos meios de cultura de bacteriologia, deixando de ser feita quando do seu isolamento do meio de Agar Sabouraud. Desta maneira, consideramos como potencialmente patogênicas Candida $s p$. e outras leveduras que, isoladas nos meios de bacteriologia, estivessem, em uma avaliação semi-quantitativa, em quantidades consideradas moderadas ou superior 13 . Classificamos como flora normal todos os outros casos de Candida sp. e outras leveduras.

A avaliação da presença ou não de processo infla. matório entra como a terceira variável, de extrema importância na compreensão do problema. $\mathrm{Na}$ comparação da microflora dos dois grupos, com ou sem processo inflamatório, a semelhança da composição da flora bacteriana vaginal e/ou cervical como um todo fica por conta da presença de bactérias como: Corynebacterium sp., Staphylococcus epidermidis, Lactobacillus sp., Streptococcus não hemolítico que, fazendo parte da flora vaginal normal, podem estar presentes também em processos inflamatórios.

Numa avaliação em que entra o componente se: mi-quantitativo, G. vaginalis destaca-se como um patógeno importante de vaginite e cervicite, neste grupo em estudo. Em $40 \%$ das pacientes que apresentaram alterações citológicas indicativas de processo inflamatório, G. vaginalis foi isolado como único patógeno, predominante ou não. A presença ocasional de G.vaginalis como microorganismo predominante na cultura, em pacientes sem atipia inflamatória, não invalida o seu papel patogênico, uma vez que outros microorganismos já aceitos como patogênicos, como a T. vaginalis, podem ocorrer na ausência de inflamação15. Em três pacientes do presente estudo, em que à cultura observou-se G.vaginalis predominante com citologia normal, queremos destacar que o esfregaço citológico e o esfregaço corado pelo Gram apresentavam uma predominância evidente de Lactobacillus $s p$, indicando possivelmente, que havia predominância deste microorganismo, mas que a não utilização de técnica específica para o seu isolamento fez com que $G$.vaginalis surgisse como predominante. Em nossa opinião, evidenciado o importante papel patogênico da $G$. vaginalis, não se justifica a sua inclusão no grupo das chamadas vaginites inespec ífic as $1,9,18$. $\mathrm{Tal}$ designação deveria restringir-se àqueles casos em que apesar da citologia inflamatória, não foram isolados patógenos reconhecidos ${ }^{2}$.

$\mathrm{Na}$ comparação de pacientes em uso de métodos contraceptivos com grupo controle, não houve diferenças marcantes na microflora, mas o pequeno número de casos estudados não permite uma avaliação conclusiva.

\section{AGRADECIMENTO}

A Dra. Indira Marxsen Chagas, da Matemidade Climério de Oliveira que gentilmente cedeu suas pacientes para esta pesquisa.

GUERREIRO, H.M.N. et al. [Vaginal flora and correlation with cytological aspects]. Rev.Saúde públ., S.Paulo, $20: 415 \cdot 20,1986$.

ABSTRACT: This work is an attempt to throw more light on the pathogenicity of microorganisms of the vaginal flora, specially those of the so-called nonspecific vaginitis. An attempt is made to determine the value of cytology as a method for the identification of vaginal flora, by the study of microbiologic cultures, fresh and Gram stain direct exam and citology of the cervico-vaginal specimens of 97 patients. Among microorganisms with clinical significance, Gardnerella vaginalis was the most frequently isolated organism, $48,4 \%$, followed by Trichomonas vaginalis, $10.3 \%$, Candida albicans, $7.2 \%$ and Neisseria gonorrhoeae, $1.1 \%$. Cytologic changes typical of cervicitis and/or vaginitis were seen in the majority of cases of G. vaginalis, C.albicans, and in all cases of T.vaginalis. The importance of a semi-quantitative evaluation of the vaginal flora on the culture plates was stressed. In the evaluation of cytology as a diagnostic method of the vaginal microflora, we observed that it was the best of the two methods used in the identification of $T$.vaginalis and that it was capable of detecting the presence of about $50 \%$ of C.albicans. In the diagnosis of G.vaginalis cytology was positive in $48.9 \%$ of cases. It is of note that of 31 cases of positive cytologic smear, eight had negative culture for $G$. vaginalis, even though organisms such as Haemophilus sp or Corynebacterium sp had been isolated in these cases.

UNITERMS: Vagina, microbiology. Vagina, citology. Vaginitis, diagnosis. Cervicitis, diagnosis. 


\section{REFERENNCIAS BIBLIOGRÁFICAS}

1. AMSEL, R. et al. Nonespecific vaginitis. Amer.J.Med., $74: 14-22,1983$.

2. ESCHENBACH, D.A. Vaginal in fection. Clin. Obstet. Gynec., 26: 182-202, 1983.

3. GALLIS, H.A. Microbial ecology and normal flora of the human body. In: Jok lik, W.K. et al., ed. Zynnsser microbiology. 17th ed. New York, Appleton-Century Crofts, 1980. p. 405-11.

4. GORBACH, S.L. et al. Anaerobic microflora of the cervix in healthy women. Amer.J.Obstet.Gynec., 117:1053-5, 1973.

5. GREENWOOD, J.R. et al. Haemophilus vaginalis (Corynebacterium vaginale): method for isolation and rapid biochemical identification. Hlth Lab.Sci., $14: 102-6,1977$.

6. GUPTA, P.K. et al. Cytologic investigations in Chlamydia infection. Acta cytol., 23 : 315-20, 1979.

7. HAMMANN, R. A reassessment of the microbial flora of the female genital tract, with special reference to the occurrence of bacteroides species. J. med.Microbiol., $15: 293-302,1982$.

8. HELLER, C.J. Neisseria gonorrhoeae in Papanicolaou smear. Acta cytol., 18: 338-40, 1974.

9. ISENBERG, H.D. \& PAINTER, B.G. Indigenous and pathogenic microorganisms of man In: Lennette, E.H. et al, ed. Manual of clinical microbiology. 2nd ed. Washington, D.C., American Society of Microbiology, 1974. p. $45-58$.

10. JONES, B.M. Gardnerella vaginalis associated vaginitis. Med.Lab.Scl., 40:53-7, 1983.

11. LEVISON, M. et al. Quantitative bacteriology of the vaginal flora in vaginitis. Amer.J.Obstet.Gynec., 133 : $139-44,1979$.
12. MARTINEZ, RL. et al. Significación patogénica de Candida en pacientes con vaginitis. Ginec. Obstet. Mexico, 50: 145-8, 1982.

13. MARTINS, J.A. et al. Flora bacteriana cérvico-vaginal. I - Composiçāo. Ginec. Obstet.bras., 5 : 71-7, 1982.

14. MEHTA, P.V. Vaginal flora. J.reprod.Med., $27: 455-8$, 1982.

15. MENDEL, E.B. \& HABERMAN, S. The vaginal ecology and its relationship to symptoms in vaginitis. South.med.J., 58: 374-8, 1965.

16. NOVOTNY, T. Vaginal disease. Postgrad.Med., 73 : $303-7,1983$.

17. OHM, M.J. \& GALASK, RP. Bacterial flora of the cervix from 100 prehysterictomy patents. Amer. J.Obstet.Gynec., $122: 683-7,1975$.

18. PHEIFER, T.A. et al. Nonespecific vaginitis. New Engl.J.Med., 298: 1429-33, 1978.

19. WIED, G.L. The interpretation of inflamatory reactions in the vagina, cervix and endocervix by means of cy tologic smears. Amer.J.clin.Pathol., 28 : 233-42, 1957.

20. ZUNIN, A. et al. Studio della flora bactterica vaginale in condizioni normali $e$ in quadri patologici di frequente riscontro ginecologico. G.Batt.Virol.Immun., $74: 320-34,1981$.

Recebido para publicação em 17/12/1985

Reapresentado em 19/08/1986

Aprovado para publicação em 29/08/1986. 